\title{
The Impact of a Collaborative Consultation Service Delivery Model for Rural Deaf/Hard of Hearing Students
}

\author{
Holly F. Pedersen ${ }^{1} \&$ Ann Beste-Guldborg ${ }^{2}$ \\ ${ }^{1}$ Department of Special Education, Minot State University, Minot, ND, USA \\ ${ }^{2}$ Department of Communication Disorders, Minot State University, Minot, ND, USA \\ Correspondence: Holly F. Pedersen, EdD, Department of Special Education, Minot State University, 500 \\ University Ave. W., Minot, ND 58707, USA. E-mail: holly.pedersen@minotstateu.edu
}

Received: May 21, 2019

Accepted: June 20, 2019 Online Published: July 4, 2019

doi:10.5539/jel.v8n5p1

URL: https://doi.org/10.5539/jel.v8n5p1

\begin{abstract}
Educating students who are deaf and hard of hearing $(\mathrm{D} / \mathrm{HH})$ is complex; compounding this complexity is the situation in rural areas, where the incidence levels are lower, students are more spread out, and the availability of specialty staff is more limited. The purpose of this mixed-methods action research study was to examine the impact of a collaborative consultation (CC) service delivery model on the knowledge and self-efficacy of school professionals who serve students who are $\mathrm{D} / \mathrm{HH}$ in rural areas. A case study research design was used on a team of 3 school professionals from a rural school in the Upper Midwest. Findings indicated that $\mathrm{CC}$ increased the knowledge and self-efficacy of school professionals serving rural D/HH students. Implications for social change pertain to education administrators, inservice educators, and D/HH students.
\end{abstract}

Keywords: deaf, hard of hearing, collaborative consultation, rural education, deaf education

\section{Introduction}

Since its inception, special education law has held individualized education, and a continuum of services and placement options provided in the least restrictive environment as primary tenants. In the past, the field of deaf/hard of hearing $(\mathrm{D} / \mathrm{HH})$ education has been slow to embrace the concept of inclusion (Moores \& Martin, 2006); however, the trend of students with hearing loss being educated in inclusive settings has increased significantly in the past two decades (GRI, 2011). This trend is expected to continue due to such factors as universal newborn hearing screening and early intervention, better amplification technology, and improved health care resulting in a decrease in the incidence of profound deafness (Luckner, 2006b).

However, simply placing a student with hearing loss (or any disability) in an inclusive setting does not ensure access. The role of specialized instruction, including accommodations and modifications, is essential in the student success equation. Students who are $\mathrm{D} / \mathrm{HH}$ represent a very heterogeneous group and issues in the education of these students are complex (Scheetz, 2012). Difficulties in teacher training, recruitment, and retention exist nationwide related to low-incidence disabilities, including deafness (AAEE, 2008). These difficulties are augmented in rural settings due to lack of social and financial incentives for teachers to come to and stay in these areas. In fact, data suggest that the problem may be more significant in the Dakotas than in other Midwest states (GRI, 2011) where students who are D/HH are spread out amongst their smaller, geographically isolated home-town schools, which typically do not employ teachers of the deaf/hard of hearing (TODHHs) and the students' general education teachers and other available support professionals are often unprepared to meet the unique instructional needs of children who are D/HH (Montgomery, 1999; Luckner, 2002).

The problem is that, while the availability of skilled teachers has been identified as the highest predictor of quality education services for children with low-incidence disabilities (Rude, Jackson, Correa, Luckner, Muir, \& Ferrel, 2005), D/HH students in rural states have limited or no access to highly qualified teachers who are equipped to meet their unique educational, communicative, social, and vocational preparation needs. This puts rural students who are $\mathrm{D} / \mathrm{HH}$ at significant risk for communicative, academic, and social failure, decreasing their chances of transitioning into productive adult life. No consistent, validated methods for addressing this problem in the rural plains have been implemented nor does the literature in the field offer such data. 


\subsection{Issues in Educating Deaf and Hard of Hearing Students}

The full scope of how any degree of hearing loss can impact a child's development is usually underestimated. The potential impact of inadequate communication interactions on the language development of children who are $\mathrm{d} / \mathrm{hh}$ results in a "domino effect" subsequently affecting their general knowledge base, vocabulary development, literacy skills, and higher order thinking skills (Marschark \& Hauser, 2008; Paul, 2009); the link between language skills and literacy acquisition for all students, including those with hearing loss is well established (Hirsch, 2010; Paul, 2009; Trezek, Wang, \& Paul, 2010).

The concepts of educational placement and service personnel have been highly debated in the field of deaf education (Andrews, 2006; Moores, 2008). These debates are considered moot in the context of the current study. While the decision of student placement as determined through the Individualized Education Plan (IEP) process must be followed, the fact remains that the majority of children with hearing loss are and will continue to be included in general education settings (USGAO, 2011). Research supports that quality of instruction has a greater influence on student learning than does time children with disabilities spent in the general education classroom (Hocutt, 1996). Consequently, special and general educators and other related service personnel must focus together on understanding and implementing effective instructional strategies for students with hearing loss that are applicable in a variety of educational settings, including the general education classroom. The official position of the Joint Committee of the American Speech-language and Hearing Association and the Council on Education of the Deaf is that the needs of children who are $\mathrm{D} / \mathrm{HH}$ are best served when speech-language pathologists (SLPs) and TODHHs work collaboratively (ASHA, 2004).

While early literature reports that SLPs, regular education teachers and other staff are often unprepared and feel less than confident to meet the unique needs of children who are D/HH (Luckner, 1991; Montgomery, 1999; Powers \& Schwilk, 1997), more recent research suggests that university preparation programs are beginning to address this topic (Houston, 2010; Wray \& Flexer, 2010). Furthermore, research documents that regular educators and other personnel feel more comfortable and include more characteristics of effective instruction for $\mathrm{D} / \mathrm{HH}$ students if in-service training and support are provided, particularly when the information provided is also applicable to hearing students (Gooden \& Rogers, 2003). The personnel challenges presented by low incidence disabilities in rural states necessitate various staffing configurations; in-service training in the context of CC may be a viable method for enhancing the knowledge and skills of direct service providers with the goal of improving educational outcomes for $\mathrm{D} / \mathrm{HH}$ students. While previous studies have identified deficits related to personnel serving students who are $\mathrm{D} / \mathrm{HH}$, the proposed study strives to further add to the research base on this topic by exploring solutions to personnel deficits, which ultimately impact student learning.

\subsection{Collaborative Consultation}

Collaborative practices have been recommended and even mandated in special education law to address the needs of students with disabilities. Collaborative consultation (CC) has been proposed as a specific model to address the needs of rural students who are D/HH (Luckner, Rude, \& Sileo, 1989). CC "is an interactive process that enables groups of people with diverse expertise to generate creative solutions to mutually defined problems. The outcome is enhanced and altered relative to solutions that group members might produce independently" (Idol, Paolucci-Whitcomb, \& Nevin, 2000, p. 13). The CC model is triadic with the components of knowledge, interpersonal communication skills, and intrapersonal reflection skills having equal weight in the process. Collaborative relationships between diverse professionals can improve less experienced team members perceptions that they can successfully teach students with disabilities (Tannock, 2009; Brownell \& Pajares, 1996).

\subsection{Teacher Efficacy and Knowledge}

There is clear theoretical support for the use of collaborative practices in school settings. Bandura's (1977a; 1986) social learning theory emphasizes the role of social interaction in the learning process. Bandura suggests that behaviors and skills can not only be acquired from direct participation, but can be learned vicariously through observation, modeling, discussion, and even social persuasion. A major tenant of social cognitive theory is perceived self-efficacy, which Bandura (1977b) describes as the mediator between one's thoughts and beliefs and one's actions. Perceived self-efficacy refers to, "a person's estimate that a given behavior will lead to certain outcomes" and, "the conviction that one can successfully execute the behavior required to produce the outcome" (Bandura, 1977a, p. 193). An individual's perceived self-efficacy influences his/her behavior in three main ways: 1) whether or not he/she will engage in a particular task, 2) the effort and persistence he/she will exert during the task, and 3) the thought patterns and emotional reactions he/she will demonstrate (Bandura, 1986).

The concept of self-efficacy applied to the field of education is still evolving (Fives, 2003) and the literature base 
is large and diverse. Bandura (1997) stated that teachers' self-efficacy beliefs are directly linked to instructional practices and learner outcomes. Teachers who have higher self-efficacy beliefs are more likely to engage in difficult teaching tasks, stick with the task longer and experience less stress doing it. Furthermore, teacher self-efficacy must be examined in context-specific tasks rather than in general terms (Tschannen-Moran \& Woolfolk Hoy, 2001), thus the need to examine teacher self-efficacy in the context of a specific educational task (i.e., teaching students with hearing loss) is evident.

\subsection{The Relationship Amongst Knowledge, Teacher Efficacy, and Collaborative Consultation}

There is evidence that knowledge, teacher efficacy, and CC are both interactional and interdependent (Nunn \& Jantz, 2009). While several decades have passed since federal law first introduced inclusionary practices for students with disabilities, pre-service programs for general education professionals are still lacking. Kosko and Wilkins (2009) found that the majority of general education teachers in their study wanted to include students with disabilities in their classrooms but felt largely unprepared to do so. Providing general education professionals with knowledge about students with specific types of disabilities, their educational consequences and inclusionary strategies results in increased teacher efficacy (Hutzler, Zach, \& Gafni, 2005). Reciprocally, Erdem and Demirel (2007) reported that increased teacher efficacy is what motivates teachers to pursue knowledge and skill development. Self-efficacy is what motivates an individual from knowledge to action. Research in education of children with and without disabilities suggests that teacher efficacy is a strong predictor of teacher change and is highly correlated with sustained use of research-based instructional practices (Jerald, 2007; Gersten, Chard, \& Baker, 2000). Fives (2003) suggested that collaborative teaching practices between general and special educators can positively influence both teacher efficacy and teacher abilities. Finally, Deaver (2005) found that, in order for CC to successfully influence teacher knowledge and efficacy, the components of establishing positive relationships and adult learning strategies must be emphasized.

The purpose of this study was to examine the impact of $\mathrm{CC}$ on the knowledge and self-efficacy of professionals serving students who are $\mathrm{D} / \mathrm{HH}$ in rural settings. The researchers posed the following research questions, 1) How does participation in a collaborative consultation model affect the self-efficacy of participants serving students who are $\mathrm{D} / \mathrm{HH}$ ? 2) How does participation in a collaborative consultation model affect disability specific knowledge of participants serving students who are $\mathrm{D} / \mathrm{HH}$ ? and 3) What are participants' perceptions regarding the collaborative consultation model during participation in the project? The study hypothesized that both professional self-efficacy and disability specific knowledge would be positively impacted by participation in CC and that examining perceptions of $\mathrm{CC}$ participation would inform future professional development activities relative to $\mathrm{CC}$.

\section{Method}

Since both quantitative and qualitative methods are recommended for examining CC (Lewandowski, 2005), the current study utilized a mixed method design with a concurrent nested approach. The quantitative component consisted of a pre/post intervention tool, designed to measure change in both participant self-efficacy and participant knowledge relevant to the education of children who are $\mathrm{D} / \mathrm{HH}$, as a result of $\mathrm{CC}$. The qualitative data was collected via electronic participant pre-post intervention interviews and written participant reflective journals done during the intervention period.

\subsection{Participants}

The case was a team of school professionals newly serving one student with hearing loss and had limited access to a TODHH. This school team consisted of three members in addition to the researcher, who functioned as the team's TODHH. Team members included a general education teacher, a special education teacher, and a resource room teacher. While parents are integral members of any child's educational team and are required members for children receiving special education services, the purpose of this study was to investigate the effects of $\mathrm{CC}$ on professionals.

\subsection{Instrumentation}

A researcher developed survey was used to measure the impact of $\mathrm{CC}$ on participants' knowledge and self-efficacy related to teaching $\mathrm{d} / \mathrm{hh}$ students. While several teacher efficacy scales have been developed, including those related to teaching children with some types of disabilities, none specifically address teaching children who are d/hh. The STASK-D/HH (School Team Assessment of Self-efficacy and Knowledge Deaf/Hard of Hearing) measured both independent variables of knowledge and self-efficacy and was designed according to Bandura's (2006) Guide for Constructing Self-Efficacy Scales. It consists of 25 items (exclusive of demographic data) related to school professionals' knowledge regarding education of students who are $\mathrm{d} / \mathrm{hh}$. 
Items for the STASK-D/HH are based on the Council for Exceptional Children Knowledge and Skill Base for all Beginning Special Education Teachers of Students who are Deaf and Hard of Hearing (CEC, 2012). Participants answered each knowledge item and then rated the strength of their belief in the correctness of their answer on a five-point scale from 1 (not at all confident) to 5 (very confident). Content validity of the STASK-D/HH was established through the development of a table designed to show the correlation of items to the CEC-CED knowledge statements. The STASK-D/HH was pilot tested to establish test-retest reliability and face validity for the measure.

\subsection{Data Collection}

The STASK-D/HH was individually administered during the first and last in-service sessions. Electronic pre and post intervention interviews and participant journaling were used to gather qualitative information regarding participant perceptions of the CC process.

\subsection{Data Analysis}

Data from the STACK-D/HH pre and post tests were analyzed using descriptive statistics (means, frequencies, and standard deviations). In order to measure the change in overall score of the group between pre and post scores, a repeated measures t-test was used. This statistic was also computed between pre and post scores for each survey item individually. Statistical limitations of the repeated-measures $t$, specifically increased chance of type one errors, is noted. However, this method was chosen in order to measure change between each item.

The data from the pre and post intervention interviews and the participants' journal entries were qualitatively analyzed according to Hatch's (2002) procedures for interpretive analysis. The analyzed quantitative data and the qualitative summary was integrated at this point for overall interpretation.

\section{Results}

To look for overall differences in participant knowledge and self-efficacy between the pre-post survey data, a paired samples t-test was employed, using the totaled number of survey questions for each participant $(n=25)$ as the unit of measure. As can be seen in Table 1, the mean knowledge score increased from 57.08 on the pre-survey to 81.16 on the post survey. The mean self-efficacy score increased from 8.48 on the pre-survey to 13.04 on the post survey.

Table 1. Paired samples statistics

\begin{tabular}{llllll}
\hline & & Mean & N & Std. Deviation & Std. Error Mean \\
\hline Pair 1 & PreKnow & 57.080 & 25 & 37.906 & 7.581 \\
& PostKnow & 81.160 & 25 & 29.136 & 5.827 \\
Pair 2 & PreSE & 8.480 & 25 & 3.229 & .646 \\
& PostSE & 13.040 & 25 & 1.567 & .313 \\
\hline
\end{tabular}

As seen in Table 2, the results of the paired samples t-test indicate a significance level of .016 for the knowledge variable and .000 for the self-efficacy variable. The results indicate that there is a significant difference in the pre-post scores of participants for both the knowledge and self-efficacy variables $(\mathrm{p} \leq .05)$.

Table 2. Paired samples test

\begin{tabular}{|c|c|c|c|c|c|c|c|c|c|}
\hline & & \multicolumn{8}{|c|}{ Paired Differences } \\
\hline & & \multicolumn{8}{|c|}{$\begin{array}{l}95 \% \text { Confidence Interval } \\
\text { of the Difference }\end{array}$} \\
\hline & & $\overline{\text { Mean }}$ & Std. Deviation & $\begin{array}{l}\text { Std. Error } \\
\text { Mean }\end{array}$ & Lower & Upper & $\mathrm{t}$ & $\mathrm{df}$ & $\begin{array}{l}\text { Sig. } \\
\text { (2-tailed) }\end{array}$ \\
\hline Pair 1 & PostKnow - PreKnow & 24.080 & 46.625 & 9.325 & 43.326 & 4.834 & 2.582 & 24 & .016 \\
\hline Pair 2 & PostSE - PreSE & 4.560 & 2.945 & .589 & 5.776 & 3.344 & 7.742 & 24 & .000 \\
\hline
\end{tabular}

In order to further analyze the survey results, the degree and directionality (increase or decrease) of change in both knowledge and self-efficacy for the pre and post scores was calculated by question. This was done by first subtracting the total pre-survey knowledge questions correct from the total post-survey knowledge questions correct. Next, the total Likert pre-survey scores were subtracted from the total Likert post-survey scores. These data are displayed in Table 3. For the knowledge variable, 12/25 questions showed an increase in being answered 
correctly from pre to post. Ten out of 25 questions showed no change, and 3/25 questions showed a decrease in being answered correctly from pre to post. The self-efficacy ratings increased for all questions, except for questions 10 and 16, which showed no change between pre and post.

Table 3. Degree and direction of pre-post change by survey question

\begin{tabular}{|c|c|c|c|}
\hline \multicolumn{2}{|c|}{ Survey Questions 1-25 } & \multirow{2}{*}{$\begin{array}{l}\text { Percentage of } \\
\text { Knowledge Change } \\
-66\end{array}$} & \multirow{2}{*}{$\begin{array}{l}5 \text { Point Likert Scale } \\
\text { Self-efficacy Change } \\
+5\end{array}$} \\
\hline 1) & In general, the consonant sounds are louder than the vowel sounds. & & \\
\hline 2) & Minimal hearing loss is not educationally significant. & 0 & +2 \\
\hline 3) & Hearing loss can be accurately diagnosed within a few weeks of birth. & +66 & +3 \\
\hline 4) & \multicolumn{2}{|l|}{$\begin{array}{l}\text { According to IDEA, responsibility to ensure hearing aids worn in school are functioning properly lies }+33 \\
\text { with the school district. }\end{array}$} & +5 \\
\hline 5) & Middle ear pathology is responsible for a high percentage of childhood hearing loss. & -33 & +4 \\
\hline 6) & $\begin{array}{l}\text { Using visual mapping strategies is an effective means of organizing information for children with } \\
\text { hearing loss. }\end{array}$ & 0 & +6 \\
\hline 7) & The incidence of profound hearing loss in the U.S. is on the rise. & +66 & +3 \\
\hline 8) & Children with hearing loss learn information incidentally from their environment. & 0 & +5 \\
\hline 9) & $\begin{array}{l}\text { A child with minimal or unilateral hearing loss is } 20 \text { times more likely to fail a grade by age } 10 \text { than } \\
\text { his hearing peers. }\end{array}$ & 0 & +1 \\
\hline 10) & \multicolumn{2}{|l|}{$\begin{array}{l}\text { Allowing a student to give their answer to a test item in another format (e.g. through sign language or } 0 \\
\text { spoken language) is an acceptable accommodation. }\end{array}$} & 0 \\
\hline 11) & Nonverbal or performance intelligence tests are of questionable validity for use with the deaf. & -66 & +3 \\
\hline 12) & \multicolumn{2}{|l|}{$\begin{array}{l}\text { An educational interpreter should decide to change the complexity of instructional language if needed } 0 \\
\text { by the deaf student. }\end{array}$} & +3 \\
\hline 13) & $\begin{array}{l}\text { Mediated instruction, instructional conversation and scaffolding are all research-based strategies for } \\
\text { teaching students who are } \mathrm{d} / \mathrm{hh} \text {. }\end{array}$ & +33 & +5 \\
\hline 14) & \multicolumn{2}{|l|}{$\begin{array}{l}\text { The use of graphic organizers should be systematically reduced in the instruction of students who are } 0 \\
\text { d/hh lest they become dependent on these tools. }\end{array}$} & +2 \\
\hline 15) & $\begin{array}{l}\text { If the student who is } \mathrm{d} / \mathrm{h} h \text { has access to the general education curriculum he/she will not require } \\
\text { individualized preparation for post-secondary transition. }\end{array}$ & +33 & +2 \\
\hline 16) & $\begin{array}{l}\text { The percentage of children with hearing loss who have other disabilities that can affect their } \\
\text { educational progress a. } 10 \% \text {, b. } 20 \% \text {, c. } 40 \% \text {, d. } 80 \%\end{array}$ & 0 & 0 \\
\hline 17) & $\begin{array}{l}\text { Children with hearing loss have more limited access to language used in everyday routines because: } \\
\text { a. they lack quality amplification, b. they miss out on incidental learning, c. they experience fewer } \\
\text { daily routines, d. they have a higher incidence of ADHD }\end{array}$ & +66 & +4 \\
\hline 18) & \multicolumn{2}{|l|}{$\begin{array}{l}\text { a. additional time needed for processing, b. limited schema for organizing incoming information, c. } \\
\text { an additional level of stress, d. all of the above }\end{array}$} & +2 \\
\hline 19) & $\begin{array}{l}\text { The approach in which American Sign Language is developed as the child's first language is: } \\
\text { a. total communication, b. simultaneous communication } \\
\text { c. bilingual-bicultural, d. auditory-oral }\end{array}$ & +100 & +9 \\
\hline 20) & $\begin{array}{l}\text { Current research indicates that children had significantly better language competence when their } \\
\text { hearing loss was identified and intervention begun by the age of: } \\
\text { a. } 2 \text { months, b. } 6 \text { months, c. } 2 \text { years, d. } 5 \text { years }\end{array}$ & 0 & +8 \\
\hline 21) & $\begin{array}{l}\text { A research-based strategy to enhance literacy in students who are } \mathrm{d} / \mathrm{hh} \text { is: } \\
\text { a. the Language Experience Approach, b. Reading Milestones, c. Kansas Sentence Writing Strategy, } \\
\text { d. none of the above }\end{array}$ & +33 & +8 \\
\hline 22) & $\begin{array}{l}\text { More than }- \text { of children with hearing loss are born into families with normal-hearing parents. } \\
\text { a. } 20 \% \text {, b. } 40 \% \text {, c. } 60 \% \text {, d. } 90 \%\end{array}$ & +100 & +6 \\
\hline 23) & $\begin{array}{l}\text { When determining the LRE for a student who is } \mathrm{d} / \mathrm{hh} \text {, the team should consider all of the following } \\
\text { except: } \\
\text { a. linguistic needs, b. academic level, c. severity of loss, d. communication needs and the child's and } \\
\text { family's preferred mode of communication. }\end{array}$ & +66 & +9 \\
\hline 24) & $\begin{array}{l}\text { The three main variables to consider with respect to classroom acoustics are: } \\
\text { a. reverberation, noise levels, and signal to noise ratio, b. hearing loss of student, voice level of } \\
\text { teacher, background reverberation, c. height of ceiling, type of wall covering, and hard floor vs. } \\
\text { carpet, d. noise frequency, reverberation level, and voice pitch of teacher }\end{array}$ & +66 & +9 \\
\hline 25) & $\begin{array}{l}\text { The Ling } 6 \text { Sound test includes: a. /u/, /a/, /i/, /S/, /s/ and /m/, b. /b/, /a/, /i/, /n/,/s/, c. /u/, /a/, /e/, /J/, /s/ } \\
\text { and } / \mathrm{m} /, \text { d. } / \mathrm{u} /, / \mathrm{a} /, / \mathrm{i} /, / \mathrm{J} /, / \mathrm{s} / \text { and } / \mathrm{j} /\end{array}$ & $/+100$ & +10 \\
\hline
\end{tabular}


Qualitative analysis of participant journal entries identified five themes. These themes are summarized with supporting examples and links to dependent variables in Table 4.

Table 4. Qualitative theme interpretation

\begin{tabular}{|c|c|c|}
\hline Theme & Example & Variable Linkage \\
\hline \multicolumn{3}{|c|}{$\begin{array}{l}\text { Resolved Misunderstandings/Misconceptions "I see now that I would have been apt to think a student was "choosing to Knowled } \\
\text { misbehave" when the student might be having a "bad hearing day". }\end{array}$} \\
\hline Specific D/HH Knowledge Gained & \multicolumn{2}{|c|}{$\begin{array}{l}\text { "Being as I am in a middle school environment, what really stuck with me Knowledge } \\
\text { was the fact that we need to help students become self-sufficient and able } \\
\text { to make sure they acquire the skills they will need in life." }\end{array}$} \\
\hline PD Design \& Delivery & \multicolumn{2}{|l|}{$\begin{array}{l}\text { "I found it very helpful to be able to see, touch, and try out hearing aids at } \\
\text { yesterday's inservice." }\end{array}$} \\
\hline Application of Treatment Beyond D/HH & "The handouts concerning accommodations were very helpful—not just & Knowledge \& \\
\hline Students & $\begin{array}{l}\text { for deaf/hard of hearing students, but for all students. Next school year I } \\
\text { plan to use some of the handouts you gave to compile a list of some } \\
\text { accommodations that would be useful for any/all students who have } \\
\text { difficulty comprehending or keeping up with the material presented." }\end{array}$ & Self-Efficacy \\
\hline Reflections on Teaching Self-Efficacy & $\begin{array}{l}\text { "The more I've heard and read, the less adequate I began to feel as a } \\
\text { classroom teacher, who has had D/HH students at various levels in my } \\
\text { classroom. There is so much to know about hearing loss." }\end{array}$ & Self-efficacy \\
\hline
\end{tabular}

\section{Discussion}

The findings from the quantitative data analysis indicated that both professionals' knowledge and self-efficacy significantly increased after participation in the CC process. While the knowledge variable significantly increased overall, it is noted that participants showed no change in their knowledge of some survey items from pre to post survey. A pattern was evident in the content of these questions. Most of these questions addressed issues that were easily generalizable to students other than those with hearing loss. Participants also showed regression for three questions. No obvious reason for this phenomenon could be ascertained; possibly the questions were poorly worded causing participants to be unsure of the correct answer. For the self-efficacy variable, all survey question responses showed an increase in participant self-efficacy except for two. While one of these two questions similarly pertained to information generalizable to other students than those who are $\mathrm{d} / \mathrm{hh}$ the other did not. Overall, it is concluded that participation in CC increases the self-efficacy and knowledge of school professionals serving rural $\mathrm{d} / \mathrm{hh}$ students.

The qualitative research aspect of this study examined the perceptions of study participants as they moved through the process of $\mathrm{CC}$ and how these perceptions may evolve. Within the five themes that emerged from the qualitative data, theme three, specifically pertained to suggestions for inservice design and delivery. Participant's preferred activities that were hands on and had immediate application to the students they were working with. Interestingly, the other four themes are linked to either participants' knowledge, their self-efficacy or both. Theme 1: Resolved Misunderstandings/Misconceptions can be associated with both participant knowledge and self-efficacy. As participants' gain accurate knowledge, their self-efficacy may increase. Participants' comments regarding specific D/HH knowledge were a clear third theme. Theme 4: Application of Treatment Beyond D/HH Students points to both participants' knowledge and self-efficacy. Gaining knowledge of effective teaching practices and recognizing that these practices can be effective for many students not only increases the likelihood that the teacher will employ these methods, but may positively impact their self-efficacy in serving the needs to all students. The last theme contains rich information regarding how the process of CC influenced participants' teaching self-efficacy according to their own perceptions. Not surprisingly, participants shared conflicting perceptions, even within each individual. In some ways, participants felt more prepared to meet the needs of $\mathrm{d} / \mathrm{hh}$ students in their classrooms; however, they also indicated that realizing the complexity of needs of students with hearing loss made them feel overwhelmed and unsure of their ability to effectively educate $\mathrm{d} / \mathrm{hh}$ students.

Further qualitative analysis of the pre-post interview used for triangulation purposes also supports the conclusion that knowledge and self-efficacy are positively influenced by the $\mathrm{CC}$ process. Both the quantitative and qualitative findings support the conclusion that the disability specific knowledge and the self-efficacy of school professionals serving $\mathrm{d} / \mathrm{hh}$ students is favorably impacted by CC. It is further concluded that the CC service delivery model is an effective method for use in the education of $\mathrm{d} / \mathrm{hh}$ students in rural settings.

While implications for positive social change are evident in this study, the researchers must acknowledge a 
potential for social change that is considered by some to be negative. Scholars in the field of deaf education have expressed disagreement with the current state of inclusive practices (Komesaroff, 2007; Moores, 2010; Sparrow, 2005). The concern from these scholars, many of whom are members of the Deaf community, is that inclusive practices jeopardize the existence of Deaf culture. The community established through residential schools for the deaf has historically been the vehicle through which Deaf culture, including American Sign Language, was transmitted from one generation of $\mathrm{d} /$ Deaf students to the next. While concern over threats to Deaf culture are valid, it is vital to note research that questions the assumption that inclusionary practices will lead to the extinction of Deaf culture. Rosen (2006) found that there were positive, if unintended, consequences of inclusive practices relative to Deaf culture. IDEIA mandates that the IEP team serving d/hh students consider the child's unique language and communication needs, including sign language. Rosen (2006) asserts that inclusive practices have led to more hearing people increasing their awareness of Deaf culture and being exposed to American Sign Language; albeit accomplished in a non-traditional way, inclusive practices may be allowing Deaf culture to be transmitted to a wider group of individuals through public schools. Increasing awareness of not only cultural and linguistic diversity, but various types of diversity, prepares all students to become better equipped to function in an evolving global society (Mittler, 2008).

\subsection{Recommendations for Further Study}

While case studies are effective methodological practice in special education (Rumrill, Cook, \& Wiley, 2011), this study was bound by the participants, location, and other variables unique to the case. Consequently, it is recommended that this study be replicated in a multiple case study approach in order to strengthen the impact and generalizability of the findings. Building the literature base of effective case studies relative to CC can serve to shed light on this complex topic (Denton, Hasbrouck, \& Sekaquaptewa, 2003; Kampwirth \& Powers, 2011).

Additionally, this study examined the effect of $\mathrm{CC}$ on change in the knowledge and self-efficacy of school professionals. Ample support was found in the literature for this research design; specifically, that increased knowledge and self-efficacy in professionals result in more effective teaching practices and, thus, improved outcomes for students. However, the current standards-focused state of education applies to all students, including those with disabilities. IDEIA re-emphasizes that data must show that students with disabilities are meeting learning objectives aligned with the general education curriculum. Few studies exist that examine the effect of collaborative practices directly on students, with or without disabilities. While Lingo, Barton-Arwood, and Jolivette (2011) note that, "measuring success of collaboration in terms of student academic outcomes is challenging" (p. 6), the field of special education must investigate the question of how indirect methods of intervention impact students.

Finally, further research is needed on how teachers of students who are $\mathrm{d} / \mathrm{hh}$ (TODHH) are being prepared, either inservice or preservice, to provide indirect services through collaborative consultation. A recent nationwide survey of TODHHs found that while indirect models of service delivery are increasing, $30 \%$ of the survey sample indicated they had received insufficient training to provide services in this manner (Pedersn \& Anderson, 2019 in press). Identification of evidence-based practices for indirect service delivery models and investigation of how they are being included in professional development and preservice preparation programs is needed.

\subsection{Conclusion}

While controversial issues specific to the field of deaf/hard of hearing education continue, the fact remains that the majority of $\mathrm{d} / \mathrm{hh}$ students are educated in inclusive settings and this trend will continue. Consequently, the need for evidence-based practices to support the education of students who are $\mathrm{d} / \mathrm{hh}$ in such settings is urgent (Luckner, 2006a). Without quality instruction, d/hh students are at high risk for academic, social, communicative, and vocational failure.

Equally important is recognition of another fact: there is a critical shortage of special education teachers nationwide and this shortage is acute in the specialty field of $d /$ hh education (Dolman, 2010; Paul, 2015). This critical shortage has led to many states creating alternate access pathways to teacher licensure, sometimes with concerning results (Rosenberg \& Sindelar, 2005). Opposition to such practices stems from concerns that alternately prepared teachers of students who are d/hh are not equipped to meet student needs (Johnson, 2004). While this is a valid concern, this study challenges the categorial assumption that alternately prepared, or alternately delivered services are lesser services. This article offers a call to action for TODHHs to become involved in addressing the teacher shortage through research and throughtful participation in developing quality solutions to the problem, without letting perfect become the enemy of good; especially when the alternative may be no involvement of a TODHH.

Dolman (2010) noted, those responsible for D/HH personnel preparation must guard against "preparing teachers 
for jobs they wish existed but which, in fact, no longer do" (p. 358). Indeed, collaborative interdisciplinary practices are not simply the latest fad, but a necessity. The small number of TODHHs available to serve an extremely dispersed number of $\mathrm{D} / \mathrm{HH}$ students makes the traditional practice of the TODHH being the only service provider impossible. Further, as the population of students who are $\mathrm{D} / \mathrm{HH}$ becomes increasingly diverse, the likelihood that one professional can effectively meet all needs is slim.

"Collaboration among all those involved in the education of deaf students is the only way to improve the educational success of deaf students ... If we cannot succeed, we cannot expect them to" (Marschak, Convertino, \& LaRock, 2006, p. 194).

\section{References}

American Association for Employment in Education (AAEE). (2008). Educator supply and demand in the United States. Columbus, OH: Author.

American Speech-Language-Hearing Association. (2004). The roles of speech-language pathologists and teachers of children who are deaf and hard of hearing in the development of communicative and linguistic competence: Position statement. ASHA Supplement, 24, in press.

Andrews, J. (2006). Inclusion: The big delusion. American Annals of the Deaf, 151(3), 295-296. https://doi.org/10.1353/aad.2006.0032

Bandura, A. (1977a). Social learning theory. Englewood Cliffs, NJ: Prentice-Hall, Inc.

Bandura, A. (1977b). Self-efficacy: Toward a unified theory of behavioral change. Psychological Review, 84(2), 191-215. https://doi.org/10.1037//0033-295X.84.2.191

Bandura, A. (1986). Social foundations of thought and action: A social cognitive theory. Englewood Cliffs, NJ: Prentice-Hall.

Bandura, A. (1997). Self-efficacy: The exercise of control. New York: Freeman.

Bandura, A. (2006). Guide for constructing self-efficacy scales. In F. Pajares \& T. Urdan (Eds.), Adolescence and education (Vol.5. Self-efficacy beliefs of adolescents, pp. 307-337). Greenwich, CT: Information Age Publishing.

Brownell, M. T., \& Pajares, F. (1996). The influence of teachers' efficacy beliefs on perceived success in mainstreaming students with learning and behavior problems: A path analysis. Florida Educational Research Council Bulletin, 27(3 \& 4), 1-24.

Cook, L., \& Friend, M. (2010). The state of the art of collaboration on behalf of students with disabilities. Journal of Education and Psychological Consultation, 20(1), 1-8. https://doi.org/10.1080/10474410903535398

Council for Exceptional Children. (2012). CEC knowledge and skill base for all beginning special education teachers of students who are deaf and hard of hearing. Retrieved from http://www.cec.sped.org

Deaver, J. (2005). A model of collaborative consultation to raise teacher self-efficacy. Doctoral dissertation, University of Colorado at Denver, 2005. ProQuest Information and Learning Company. Ann Arbor, MI (UMI No. 3184197).

Denton, C. A., Hasbrouck, J. E., \& Sekaquaptewa, S. (2003). The consulting teacher: A descriptive case study in responsive systems consultation. Journal of Educational and Psychological Consultation, 14(1), 41-73. https://doi.org/10.1207/S1532768XJEPC1401_03

Dolman, D. (2010). Enrollment trends in deaf education teacher preparation programs, 1973-2009. American Annals of the Deaf, 155(3), 353-359. https://doi.org/10.1353/aad.2010.0013

Erdem, E., \& Demirel, O. (2007). Teacher self-efficacy belief. Social Behavior and Personality, 35, 573-586. https://doi.org/10.2224/sbp.2007.35.5.573

Fives, H. (April, 2003). What is teacher efficacy and how does it relate to teachers' knowledge? A theoretical review. Paper presented at the American Educational Research Association Annual Conference. Chicago, IL.

Friend, M., \& Cook, L. (2009). Interactions: Collaboration skills for school professionals (6th ed.). Boston, MA: Allyn \& Bacon.

Gallaudet Research Institute (GRI). (2011). Regional and national summary report of data from the 2009-10 annual survey of deaf and hard of hearing children and youth. Washington, DC: GRI, Gallaudet University. 
Gersten, R., Chard, D., \& Baker, S. (2000). Factors enhancing sustained use of research-based instructional practices. Journal of Learning Disabilities, 33(5), 445-458. https://doi.org/10.1177/002221940003300505

Gooden, J., \& Rogers, W. (2003). Improving faculty knowledge of hearing loss and its effects on education. Masters action research project, Saint Xavier University and SkyLight Professional Development Field-Based Master's Program, 2003. Retrieved from EDRS database.

Hatch, J. A. (2002). Doing qualitative research in education settings. New York: SUNY.

Hocutt, A.M. (1996). Effectiveness of special education: Is placement the critical factor? Future of Children, 6, 77-99.

Hirsch Jr., E. D. (2010). Teaching content is teaching reading. Principal, 90(2), 10-14.

Houston, T. (2010). Utah State University: Cross-discipline training through the graduate studies program in auditory learning and spoken language. Volta Review, 110(2), 323-330.

Hutzler, Y., Zach, S., \& Gafni, O. (2005). Physical education students' attitudes and self-efficacy towards the participation of children with special needs in regular classes. European Journal of Special Needs Education, 20(3), 309-327. https://doi.org/10.1080/08856250500156038

Idol, L., Paolucci-Whitcomb, P., \& Nevin, A. (2000). Collaborative consultation (3rd ed.). Austin, TX: Pro-ed.

Individuals with Disabilities Education Improvement Act (IDEIA). (2004). HR 1350. 108th Congress (2004).

Individuals with Disabilities Education Improvement Act Regulations. (August 3, 2006). Retrieved from http://www.ed.gov/policy/speced/guid/idea2004.html

Jerald, C. D. (2007). Believing and achieving. Washington, DC: Center for Comprehensive School Reform.

Johnson, H. A. (2004). US deaf education teacher preparation programs: A look at the present and a vision for the future. American Annals of the Deaf, 149(2), 75-91. https://doi.org/10.1353/aad.2004.0020

Kampwirth, T. J., \& Powers, K. M. (2012). Collaborative consultation in the schools (4th ed.). Upper Saddle River, NJ: Pearson.

Komesaroff, L. (2007). Surgical consent: Bioethics and cochlear implantation. Washington, DC: Gallaudet University Press.

Kosko, K. W., \& Wilkins, J. L. (2009). General educators' inservice training and their perceived ability to adapt instruction for students with IEPs. The Professional Educator, 33(2), 1-11.

Lewandowski, K. L. (2005). A study of the relationship of teachers' self-efficacy and the impact of leadership and professional development. Doctoral dissertation, Indiana University of Pennsylvania, May 2005. ProQuest Information and Learning Company. Ann Arbor, MI

Lingo, A. S., Barton-Arwood, S. M., \& Jolivette, K. (2011). Teachers working together. Teaching Exceptional Children, 6-13. https://doi.org/10.1177/004005991104300301

Luckner, J. (2006a). Evidence-based practices with students who are deaf. Communication Disorders Quarterly, 28(1), 49-52. https://doi.org/10.1177/15257401060280010801

Luckner, J. (2006b). Providing itinerant services. In D. Moores \& D. Martin (Eds.), Deaf learners: Developments in curriculum and instruction. Washington, DC: Gallaudet University Press.

Luckner, J. (2005). Issues-Education of students who are deaf or hard of hearing. Retrieved from University of Northern Colorado National Center on Low-Incidence Disabilities web site: www.nclid.unco.edu/deafIssues.htm

Luckner, J., Muir, S., Howell, J., Sebald, A., \& Young, J. (2005). An examination of the research and training needs in the field of deaf education. American Annals of the Deaf, 150(4), 358-368. https://doi.org/10.1353/aad.2005.0042

Luckner, J. (2002). Facilitating the transition of students who are deaf or hard of hearing. Austin, TX: Pro-Ed.

Luckner, J., Rude, H., \&, Sileo, T. W. (1991). Collaborative consultation: A method for improving educational services for mainstreamed students who are hearing impaired. American Annals of the Deaf, 134(5), 301304. https://doi.org/10.1353/aad.2012.0535

Luckner, J. (1991). Consultation skills for teachers of students with hearing impairments. Volta Review, 93, 311322. 
Luckner, J. L., Harvey, R., \& Thomas, W. S. (1989). Collaborative consultation: A method for improving educational services for mainstreamed students who are hearing impaired. American Annals of the Deaf, 134(5), 301-304. https://doi.org/10.1353/aad.2012.0535

Marschark, M., Convertino, C., \& LaRock, D. (2006). Optimizing academic performance of deaf students: Access, opportunities, and outcomes. Deaf learners: New developments in curriculum and instruction, 179200.

Marschark, M., \& Hauser, P. C. (Eds.). (2008). Deaf cognition: Foundations and outcomes. New York: NY: Oxford University Press, Inc. https://doi.org/10.1093/acprof:oso/9780195368673.001.0001

Mittler, P. (2008). Planning for the 2040s: Everybody's business. British Journal of Special Education, 35(1), 310. https://doi.org/10.1111/j.1467-8578.2008.00363.x

Moores, D., \& Martin, D. (2006). Deaf Learners: Developments in curriculum and instruction. Washington, DC: Gallaudet University Press.

Moores, D. (2008). Inclusion, itinerant teachers, and the pull-out model. American Annals of the Deaf, 153(3), 273-274. https://doi.org/10.1353/aad.0.0048

Moores, D. (2010). Integration $\rightarrow$ inclusion $\rightarrow$ oblivion. American Annals of the Deaf, 155(4), 1-3. https://doi.org/10.1353/aad.0.0131

Montgomery, N. (1999). The comparison of confidence levels of speech-language pathologists in public school settings when working with students who are deaf/hard of hearing versus hearing students. Doctoral dissertation, University of Kansas. ProQuest Information and Learning Company. Ann Arbor, MI (UMI No. 9970613).

Nunn, G., \& Jantz, P. B. (2009). Factors within response to intervention implementation training associated with teacher efficacy beliefs. Education, 129(4), 599-607.

Paul, P. V. (2009). Language and deafness (4th ed.). Sudbury, MA: Jones \& Bartlett Publishers.

Paul, P. V. (2015). d/Deaf and hard of hearing with a disability or an additional disability: The need for theory, research, and practice. American Annals of the Deaf, 160(4), 339-343. https://doi.org/10.1353/aad.2015.0029

Pedersen, H. F., \& Anderson, K. A. (2019 in press). The changing role of the itinerant teacher of the deaf: A snapshot of current teacher perceptions. Journal of the American Academy of Special Education Professionals.

Powers, G. W., \& Schwilk, C. L. (March, 1997). Speech-language pathologists or teachers of the deaf/hard of hearing: Who is more qualified to serve? Paper presented at the Annual Conference of the Association of College Educators-Deaf and Hard of Hearing, Santa Fe, NM.

Rosenberg, M. S., \& Sindelar, P. T. (2005). The proliferation of alternative routes to certification in special education: A critical review of the literature. The Journal of Special Education, 39(2), 117-127. https://doi.org/10.1177/00224669050390020201

Rosen, R. (2006). An unintended consequence of IDEA: American sign language, the Deaf community, and Deaf culture into mainstream education. Disability Studies Quarterly, 26(2), 143-150. https://doi.org/10.18061/dsq.v26i2.685

Rude, H., Jackson, L., Correa, S., Luckner, J., Muir, S., \& Ferrell, K. (2005). Perceived needs of students with low-incidence disabilities in rural areas. Rural Special Education Quarterly, 24(3), 3-14. https://doi.org/10.1177/875687050502400302

Rumrill, Jr. P. D., Cook, B. G., \& Wiley, A. L. (2011). Research in special education. Designs, methods, and applications (2nd ed.). Springfield, IL: Charles C. Thomas Publisher, Ltd.

Scheetz, N. (2012). Deaf education in the 21st Century. Upper Saddle River, NJ: Pearson.

Sparrow, R. (2005). Defending Deaf culture: The case of cochlear implants. The Journal of Political Philosophy, 13(2), 135-152. https://doi.org/10.1111/j.1467-9760.2005.00217.x

Strickland, B., Eichwald, J., Cooper, L., \& White, K. (2011). Ten years of EHDI. Paper presented at the 10th Annual Early Hearing Detection and Intervention Conference. Atlanta, GA

Tannock, M. (2009). Tangible and intangible elements of collaborative teaching. Intervention in School and Clinic, 44(3), 173-178. https://doi.org/10.1177/1053451208318682 
Trezek, B., Wang, Y., \& Paul, P. (2010). Reading and deafness. Theory, research and practice. Clifton Park, NY: Delmar, Cengage Learning.

Tschannen-Moran, M., \& Woolfolk Hoy, A. (2001). Teacher efficacy: Capturing an elusive construct. Teaching and Teacher Education, 17, 783-805. https://doi.org/10.1016/S0742-051X(01)00036-1

United States Government Accountability Office (USGAO). (May 2011). Deaf and hard of hearing children: Federal support for developing language and literacy. Washington, DC: Author.

Wray, D., \& Flexer, C. (2010). University of Akron: Training speech-language pathology specialists to provide quality service to students who are deaf or hard of hearing - a collaborative preservice program. Volta Review, 110(2), 305-313.

\section{Copyrights}

Copyright for this article is retained by the author, with first publication rights granted to the journal.

This is an open-access article distributed under the terms and conditions of the Creative Commons Attribution license (http://creativecommons.org/licenses/by/4.0/). 